\title{
Snow Cover Area Detection using NDSI and Band Ratio Method
}

\author{
Priyanka Patel, DippalIsrani, Mrugendrasinh Rahevar
}

\begin{abstract}
Glaciers are a main source of water during summer in Himalayan areas. Corresponding to the historical studies, glacier is directly affected by climate change. It is important to identify change in snow cover area (Glacier area) to identify change in glacier. Remote sensing and GIS technology are used to monitor Snow covered area. This paper focuses on Sentinel-2B data of trisul glacier which is a part of Indian Himalayas to identify glacier. These multispectral images were extracted from USGS Earth Explorer. The sentinel-2B data are processed using Semi automated Classification Plugin (SCP) of QGIS tool. Snow covered area is identified by using two automated methods: Normalized Difference Snow Index (NDSI) and Band Ratio. For NDSI reflectance of visible, shortwave band is used. For Band Ratio reflectance of near infrared, shortwave infrared band is used. It is challenging to detect snow covered area from the satellite as snow covered area and cloud area have same white colure i.e. same reflectance. In this paper, represents experiments on two methods for snow area extraction on satelliteimages.
\end{abstract}

Keywords: Glacier, Band Ratio, Geospatial, NDSI, QGIS.

\section{INTRODUCTION}

A term geospatial achieve more popularity in a recent time and it defines collective data, related method, also. Geospatial data play a key role in analyzing and visualizing spatial data. The important challenge nowadays is to understand, to handle and to model the data if there are too many or too few of them. Significant problems arise while dealing with large databases or a long period of observation [1]. Information retrieval methods and algorithms used remote sensing to analyze geospatial data which is a part of geospatial analysis [2].

Remote sensing is an important part of geospatial technology that is used for environmental impact assessment process.Geospatialtoolisusedinmanyapplicationslikeair,

water, land, etc., resource monitoring, and change detection. A change in climate is a main reason of natural disasters which is observed by using geospatial data. Out of many phenomenons, glaciers are directly affected by climate change. Glaciers are one amongst the foremost landforms that represent the frozen sort of water on earth. Glacier out line are vital for various application inside glaciology. This contains glacier area change analysis [3], [4], [5], determining glacier velocity [6], [7], [8], volume modification estimations [9] and input and validation information in glacier modeling [10], [11].

Revised Manuscript Received on May 22, 2020.

* Priyanka Patel, U \& P.U. Patel Department of Computer Engineering, CSPIT, CHARUSAT, Changa, India, priyanka.patel.0546@gmail.com.

DippalIsrani, Information Technology Department, R.C. Technical Institute, dippalisrani90@gmail.com.

Mrugendrasinh Rahevar, U \& P.U. Patel Department of Computer Engineering, CSPIT, CHARUSAT, Changa, mrugendrarahevar.ce@charusat.ac.in.
Glacier studies are concerned with glacier mass which affect change in space and time. Due to rough piece of land and harsh weather in mountain range, a continuous field measurement across number of glacier is challenging. To solve this problem, remote sensing based methods to observe glacier evolution is being widely used. Remote sensing methods are recognized as to be valuable for glacier study. The existing satellite sensors are increasing and their spatial, radiometric and temporal resolutions are improved observation of Glacier (snow covered area) using remote sensing datasets like [12].Normalized Difference Snow Index (NDSI) and Band Ratio this two automated methods has been used to identify snow coveredarea.

\section{RELATEDWORK}

Till date, many methods are adopted for glacier detection such as NDSI and band Ratio. It is used to analyze visual content in snow processes. The standard technique to estimate environmental snow is to physically observe the snow cover. It is monitor with in a network of ground based meteorological stations. Snow literature delivers particular information about seasonal snow cover. Although, the spatial scale of this data is insufficient. In 19th and 20th centuries, Snow Water Equivalent (SWE) and SnowCovered Area (SCA) were keen about field assessment [14]. In 20th century, the complete global scales measured effectively by SCA and SWE. It uses images of active and passive satellites [15].

Haq et.al [16] is proposed a study on glacier monitoring using satellite images. In this paper, multispectral Landsat images taken as a source images and generate outputimages. The results of glacier mass balance were attained using Accumulation Area Ratio (AAR) and Band ratio method. The research work has shown an overall reduction in glacier area during the study period. Overall, this paper discusses in context of decrease in glaciers amount in a particular study period. kulkarni et.al [13] has suggested their research work related to monitoring snow cover by spectral reflectance to develop Normalized Difference Snow Index (NDSI). This proposed idea is based on the low reflectance in the SWIR regionandhighreflectanceofsnowinspecificvisibleregion.

In development of NDSIand Band Ratio method reflectance value is used. The study is focused on snow covered area identification. 


\section{Snow Cover Area Detection using NDSI and Band Ratio Method}

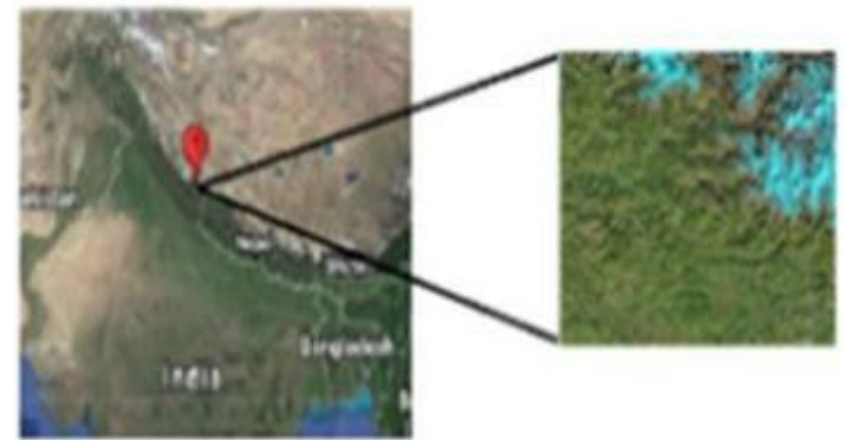

Fig. 1: study area shown as the coverage of sentinel-2B in Uttarakhand, Trisul (Path Row: 145-039)

\section{STUDYAREA}

The area used for this study is located in Bageshwar, Uttarakhand india bounded between $30^{\circ} 18^{\prime} 46 \mathrm{~N}$ and $79^{\circ} 46^{\prime} 38$ E.Trisul is them a in mountain area with a group of glaciers. The prominence of trisul glacier is $1616 \mathrm{~m}$ long and elevation of trisul is $7120 \mathrm{~m}$. The location of research area is shown in above Fig1.

\section{METHODOLOGY}

The main use is to detect the snow from the neighboring land with the help of band ratio and normalized difference snowindex.Thenforaccurateglacierclassificationthreshold value ischosen.

\section{A. SoftwareUsed}

To detect a snow accurately from the image Quantum Geographic Systems (QGIS) is mostly used. It is a free and open source tool that supports analysis and processing of geospatial information, and visualization. This kind of GIS gives user the flexibility of using different layers above each other. The QGIS 2.18.23 version is used in this paper for experimental simulations.

\section{B. DataRequired}

In this paper, operations are evaluated on standard dataset 'sentinel-2B'. The satellite images are available from https://earthexplorer.usgs.gov website which is freely available. The experiments are first listed and evaluated in QGIS using NDSI and Band Ratio. During experiment different bands of satellite image was used. The detail of bands is mentioned in Table 1.

Table I: Specification of images used in study

\begin{tabular}{|c|c|c|c|c|}
\hline Sensor & $\begin{array}{c}\text { Spectral } \\
\text { Bands }\end{array}$ & $\begin{array}{c}\text { Spectral } \\
\text { Result }\end{array}$ & $\begin{array}{c}\text { Swath } \\
\text { Width } \\
\text { (km) }\end{array}$ & $\begin{array}{c}\text { Date of } \\
\text { acquisition }\end{array}$ \\
\hline \multirow{2}{*}{ MSI } & $\begin{array}{c}\text { Band 4 } \\
- \text { Red }\end{array}$ & 10 & 31 & \\
\cline { 2 - 4 } (Multis & $\begin{array}{c}\text { Band8 } \\
\text { pectral }\end{array}$ & 10 & 106 & \multirow{2}{*}{$\begin{array}{c}23 \\
\text { Novembe } \\
\text { Image) } 2017\end{array}$} \\
\cline { 2 - 4 } & $\begin{array}{c}\text { Band11 } \\
- \text { SWIR }\end{array}$ & 20 & 91 & \\
\hline
\end{tabular}

\section{EXPERIMENT}

To find glacier using NDSI and Band Ratio following
satelliteSentinelband4,band8andband11imagesareused to get output.

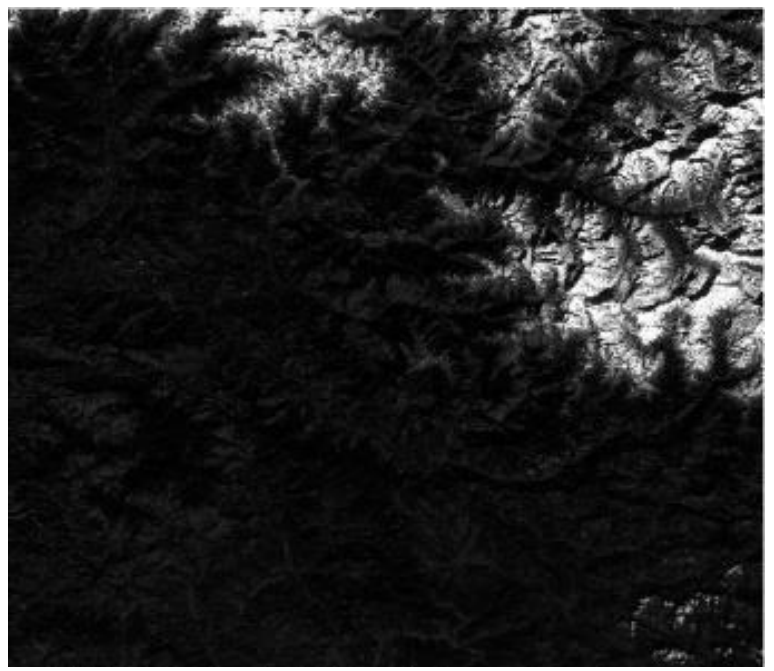

Fig. 2: band 3 sentinelimage

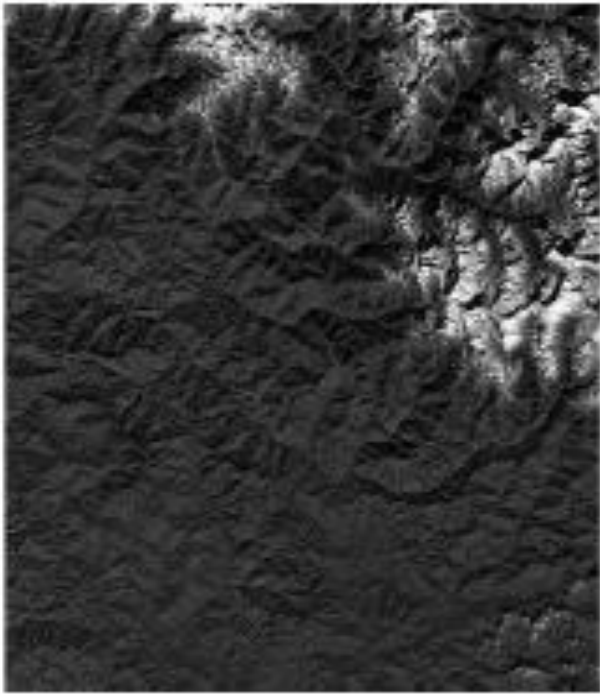

Fig.3:band8 sentinel image

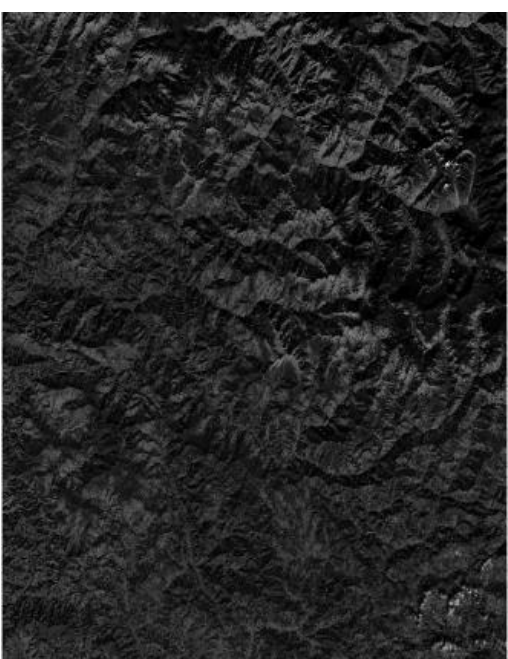

Fig. 4: band 11 sentinelimage

These three images of band 4, band 8 and band 11 are added into raster layer of QGIS. After that using raster calculator NDSI and Band Ratio is calculated. 


\section{A. Normalized Differential Snow Index(NDSI)}

In mountain area, snow mapping is difficult because of cloud cover and shadows.

This problem can be solved not fully but partially using Normalized Differential Snow Index (NDSI). Snow of NDSI is reflective in visible part more and absorptiveinshortwaveinfrared.Innormalizationallvalueis between -1 and 1 . NDSI was calculated using following formula:

\section{NDSI $=\frac{\text { Reflactance of GREEN }- \text { Reflactance of SWIR }}{\text { Reflactance of GREEN }+ \text { Reflactance of SWIR }}$}

Area of snow/ice cover area is highlighted using GREEN and SWIR band which is applied in NDSI. In the below image indicates area of snow/ ice cover as positive value. White area indicates snow/ice cover area. QGIS is used for applying above formula with threshold value to classify snow area.

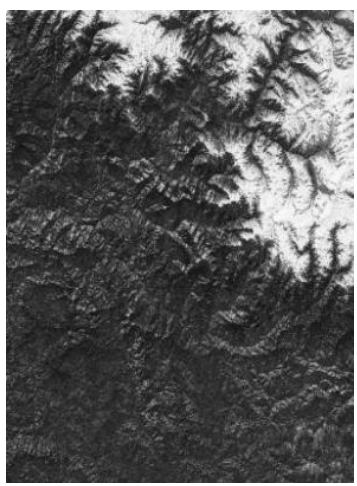

Fig. 5: NDSIoutput image

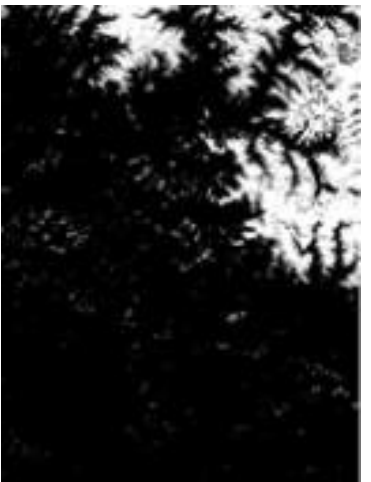

Fig. 6:NDSI output after applied threshold value

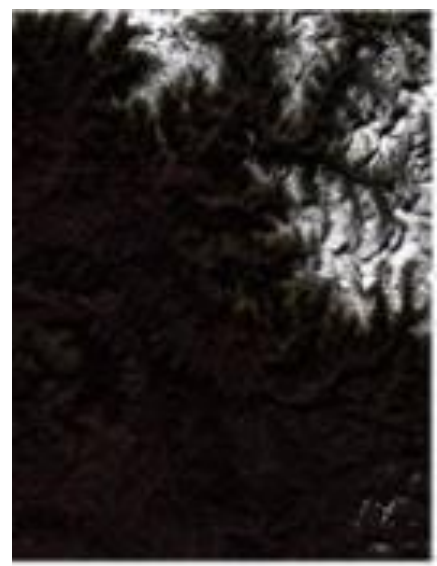

Fig. 7: NDSI modified colour image

In image bright area represent area office covered because a bright pixel indicates ice covered region. A dark pixel does not represent glaciers. By selecting threshold value dark pixelscanberemoved.Kulkarnietal.explainthresholdvalue for detecting snow is above 0.4 [13]. Band 4 image pixels value range is between 1 and 0.0158 . Band 11 image pixels value between 1 and 0.0001 . Output image pixel value range is between 0.736286 and 0.998055 .From the observation an estimation of NDSI between -1 and 1 [17] represent glacier ice. The better understanding is accomplished by exploring the histogram of NDSI method is givenbeneath:

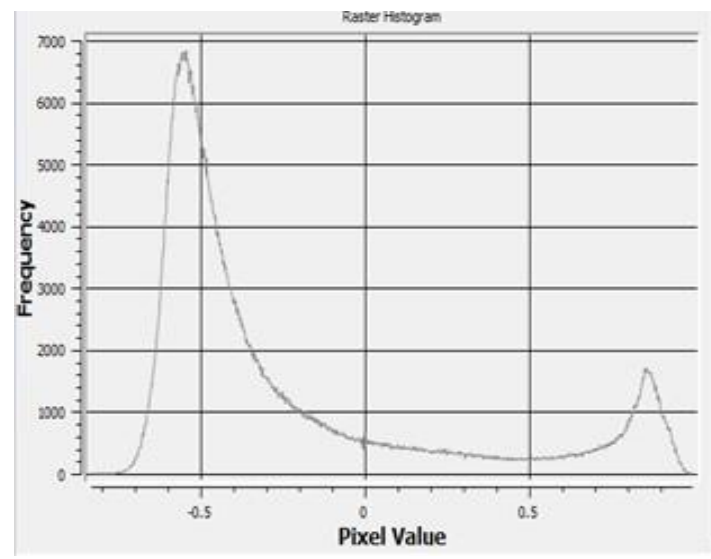

Fig. 8. : Histogram of NDSI method output image

From this raster histogram analysis, could considered that calculation is done correctly due to the pixels values lies between -1 and 1 . In these histogram strong negative pixels values of NDSI indicate cloud free pixels. The range of cloud value pixels are between -0.1 and +0.2 range. Under 0.20 pixels value are 'non snow' pixels as considered and high pixels are considered as snow pixels.

\section{B. Band Ratio}

Using remote sensing methods mapping area of snow covered is a challenging task. The reason for that is a glacier surface has a same reflectance as cloudy area into visible to near infrared area. Subsequently, at some point NDSI is not utilized consummately for snow mapping. Thus, for glacier mapping another method was produced that is band ratio. It is a semi-automated techniques used in glacier study. The two groups of bands are used Near Infrared (NIR)and Short Wave Infrared (SWIR). These two bands discriminate snow/ice surface accurately in a shadow area [18]. The interpretation of image is done effortlessly by using near infrared and visible band data that is main advantage of these two bands [19]. Following formula isused to estimate band ratio for snow/ice cover area highlighting.

$$
\begin{aligned}
& \text { Band Ratio }=\frac{\text { NIR }}{\text { SWIR }} \\
& \text { Band Ratio }=\frac{\text { Band 8 }}{\text { Band11 }}
\end{aligned}
$$

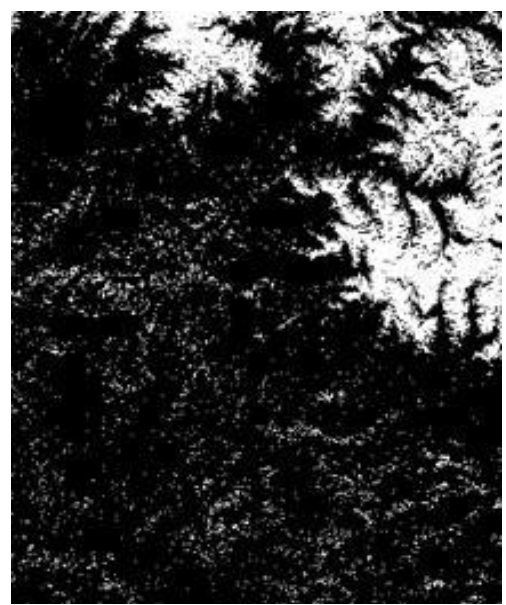

Fig. 9. Band Ratio output image 


\section{Snow Cover Area Detection using NDSI and Band Ratio Method}

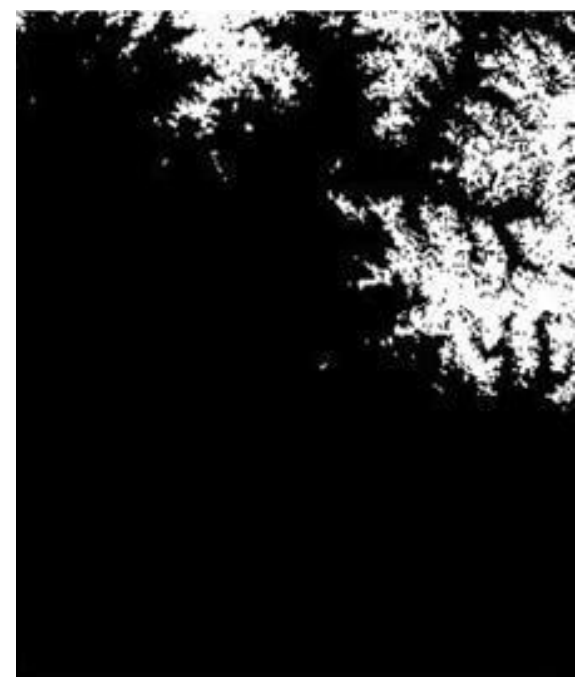

Fig. 10. NDSI output image after applied threshold value

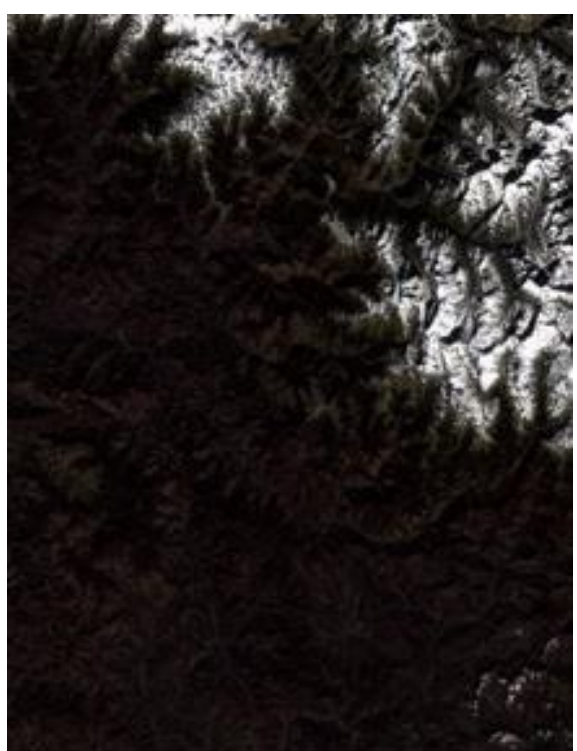

Fig. 11. Band Ratio modified colour image

Spectral response is high for snow in band 8 while band 11 has low. Dark brown represent Vegetation while bright white represent snow area in above Figure 11 see clearly. Output of image before applying threshold and after threshold is also clearly show in Figure 9 and Figure 10. Mapping clean snow/ ice threshold of band ratio is a best approach and it performs better than NDSI. QGIS tool is used to calculate band ratio image. Band 8 image pixels value range is between 0.22 and 0.837.Band11image pixels value between 0.015 and 0.410 . Output image pixel value range is between 0.167 and0.975.

As Discussed for NDSI histogram, for Band Ratio histogram is explored in Fig.12. In raster histogram pixel value range is between 0.167 and 0.975 . The range of cloud value pixels are between -0.1 and +0.2 range. Under 0.20 pixels value are 'non snow' pixels as considered and high pixels are considered as snow pixels.

Capitalize only the first word in a paper title, except for proper nouns and element symbols. For papers published in translation journals, please give the English citation first, followed by the original foreign-language citation[8].

\section{CONCLUSION}

The research work demonstrates that sentinl data are useful in extracting snow cover area because of its resolution and spatial quality. In comparison with visible band and near infrared band, snow is more reflected in infrared band. Thus, in this paper two methods are computed that includes NDSI and Band ratio. This is used to compute snow mask from image. This threshold of both methods is helpful to get accurate snow cover area with less shadow effect in image. Finally we summarize that both methods NDSI and Band ratio provides as an aid to the analysis of snow fromimage.

\section{ACKNOWLEDGMENT}

The authors would like to thank CHARUSAT Space Research and Technology Center (CSRTC) for providing required resources to carry out research work.

\section{REFERENCES}

1. Kanevski, M., A. Pozdnukhov, and V. Timonin.,"Machine learning algorithms for geospatial data. Applications and software tools", Internationa Congress on Environmental Modelling and Software,(2008), Vol. 4, pp. 320-327,2008

2. Kumar, Uttam,"Algorithms For Geospatial Analysis Using MultiResolution Remote Sensing Data.",PhD diss., G25135,2014.

3. Nuth,Christopher,JackKohler,MaxKönig,AngelavonDeschwanden, Jon Ove Methlie Hagen et al., "Decadal changes from a multitemporal glacier inventory of Svalbard.", The Cryosphere ,Vol. 7, No. 5, pp. 1603-1621,2013.

4. Bajracharya, SamjwalRatna, Sudan Bikash Maharjan, and FinuShrestha,"The status and decadal change of glaciers inBhutan from the 1980 s to 2010 based on satellite data.", Annals of Glaciology, Vol. 55, No. 66, pp. 159-166, 2014.

5. Shangguan, Donghui, Shiyin Liu, Yongjian Ding, Lizong Wu, Wei Dengetal.,"GlacierchangesintheKoshiRiverbasin,centralHimalaya, from 1976 to 2009, derived from remote-sensing imagery.", Annals of Glaciology, Vol. 55, No. 66, pp. 61-68,2014.

6. Berthier, Etienne, H. Vadon, David Baratoux, Yves Arnaud, C Vincent

etal.,"Surfacemotionofmountainglaciersderivedfromsatelliteoptical imagery.", Remote Sensing of Environment, Vol. 95, No. 1, pp. 14 28, 2005.

7. Kääb, A,"Combination of SRTM3 and repeat ASTER data for deriving

alpineglacierflowvelocitiesintheBhutanHimalaya.",RemoteSensing of Environment, Vol. 94, No. 4, pp. 463-474,2005.

8. Luckman, Adrian, Duncan J. Quincey, and D. Benn, "Quantification of Everest region glacier velocities between 1992 and 2002, using satellite radar interferometry and feature tracking.", Journal of Glaciology, Vol. 55, No. 192, pp. 596-606,2009.

9. Berthier,Etienne,EricSchiefer,GarryKCClarke,BrianMenounos, and FrédériqueRémy,"Contribution of Alaskan glaciers to sea-level rise derived from satellite imagery.", Nature Geoscience, Vol. 3, No. 2, pp. 92,2010 .

10. Gardelle, Julie, Etienne Berthier, Yves Arnaud, and A. Kaab,"Regionwide glacier mass balances over the Pamir-Karakoram-Himalaya during 1999-2011 (vol 7, pg 1263, 2013).", The Cryosphere, Vol. 7 , No. 6,pp. 1885-1886,2013.

11. Rees,H.Gwyn,andDavidN.Collins.,"Regionaldifferencesinresponse of flow in glacier-fed Himalayan rivers to climatic warming.", Hydrological Processes: An International Journal, Vol. 20, No. 10, pp. 2157-2169,2006

12. Racoviteanu, Adina E., Richard Armstrong, and Mark W. Williams., "Evaluation of an ice ablation model to estimate the contribution of melting glacier ice to annual discharge in the Nepal Himalaya.", Water Resources Research, Vol. 49, No. 9, pp. 5117-5133,2013. 
13. Kulkarni, A. V., J. Srinivasulu, S. S. Manjul, and P. Mathur.,-Field ased spectral reflectance to develop NDSI method for the snow cover monitoring.\|,JournaloftheIndianSocietyofRemoteSensing,Vol.30, No. 1- 2, pp. 73-80,2002.

14. Brown, Ross D., and Barry E. Goodison.,"Interannual variability in reconstructed Canadian snow cover, 1915-1992.", Journal of Climate, Vol.9, No. 6, pp. 1299-1318,1996.

15. Frei, Allan, Marco Tedesco, ShihyanLee, James Foster, Dorothy

16. K. Hall et al.,"A review of global satellite-derived snow products." , Advances in Space Research, Vol. 50, No. 8, pp. 1007-1029,2012.

17. Haq, M. Anul, Kamal Jain, and K. P. R. Menon.,-Change Monitoring Of Gangotri Glacier Using Satellite Imagery.l, 12th ESRI India User Conference, pp. 1-8,2011.

18. Atif, Iqra, Muhammad Ahsan Mahboob, and JavedIqbal,"Snow cover area change assessment in 2003 and 2013 using MODIS data of the Upper Indus Basin, Pakistan." Journal of Himalayan Earth Sciences,Vol. 48, No. 2, pp. 117,2015

19. Hall, D. K., J. P. Ormsby, R. A. Bindschadler, and HonnappaSiddalingaia.,-Characterization of snow and ice reflectance zones on glaciers using Landsat Thematic Mapper data.l, Annals of Glaciology, Vol. 9, pp. 1-5,1987.

20. Haq,M.Anul,KamalJain,andK.P.R.Menon,-—DevelopmentofNew ThermalRatioIndexforSnow/IceIdentification.ll,InternationalJournal of Soft Computing and Engineering (IJSCE), Vol. 1, No. 6, pp. 22312307,2012 .

\section{AUTHORS PROFILE}

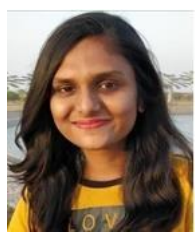

Priyanka Patel received her M.Tech in Computer Engineering from CHARUSAT University. She received her B.E. in Computer Engineering from GIDC Engineering College, Navsari. Her major research interest includes image processing, Machine Learning

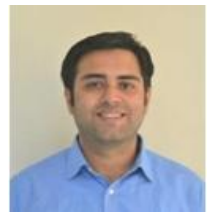

DippalIsranireceived his M. Tech in Computer Engineering from Dharmsinh DesaiUniversity He is Lecturer in InformationTechnology Department, R.C.Technical Institute. His major research interests include Computer Vision, Image Processing and Machine Learning.

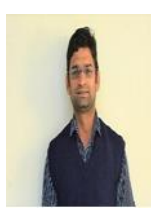

Mrugendrasinh Rahevar received his M.Tech in Computer Science and Engineering from GEC, Modasa. He is Assistant Professor in, CSPIT, CHARUSAT. His major research interests include Computer Vision, and Deep learning 